\title{
A sala de aula no contexto de (Pós) pandemia: ressignificando conteúdos de Ciências a partir de textos escreviventes
}

\author{
The classroom in the (Post) pandemic context: resignifying Science content \\ from escrevivências
}

\author{
Brenda Iolanda Silva do Nascimento \\ Graduada em Licenciatura em Ciências Biológicas pela \\ Universidade Federal do Rio de Janeiro - UFRJ \\ Estudante de Mestrado do Programa de Pós-Graduação em Educação em Ciências Saúde \\ (NUTES-UFRJ) e bolsistaCAPES. \\ Macaé, Rio de Janeiro - Brasil. \\ bisnascim@gmail.com \\ (iD) Iago Vilaça de Carvalho \\ Graduado em Licenciatura em Química pela Universidade Federal do Rio de Janeiro - UFRJ \\ Estudante de Mestrado do Programa de Pós-Graduação em Educação em Ciências e Saúde \\ (NUTE- UFRJ) e bolsista CAPES. \\ Universidade Federal do Rio de Janeiro - UFRJ. \\ Macaé, Rio de Janeiro - Brasil. \\ iago.v.carvalho@gmail.com
}

(iD) Fernanda Antunes Gomes da Costa Doutora em Letras Vernáculas pela Universidade Federal do Rio de Janeiro - UFRJ. Professora Adjunta da Universidade Federal do Rio de Janeiro - UFRJ Campus Macaé e do Programa de Pós-Graduação em Educação em Ciências e Saúde (NUTES UFRJ).

Macaé, Rio de Janeiro - Brasil. nandantunes80@gmail.com

Resumo: O contexto pandêmico impôs muitos desafios à Educação: acesso a aulas remotas, estratégias pedagógicas envolvendo docentes, discentes e família e, certamente, a urgência em abordar conteúdos que problematizem as dificuldades no enfrentamento da pandemia. Diante disso, este artigo se propõe a discutir, a partir de uma abordagem teórica, de que forma questões sociais agravadas pela chegada da COVID-19, como o acesso ao saneamento básico e à água, podem vir à tona na sala de aula de Ciências a partir de narrativas que emergem do cotidiano dos grupos mais atingidos pelo novo coronavírus. Acreditamos, assim, ser possível tecer uma Educação em Ciências comprometida com seu papel social e engajada ao enfrentamento das desigualdades sociais acentuadas na pandemia. Para isso, partimos das contribuições intelectuais de Paulo Freire, bell hooks, Carolina Maria de Jesus e Conceição Evaristo a fim de tecer reflexões acerca da importância da ressignificação dos conteúdos da Educação em Ciências.

Palavras-Chave: Ensino de Ciências. Escrevivências. Literatura. Pandemia.

Abstract: The pandemic context imposed many challenges on Education: access to remote classes, pedagogical strategies involving teachers, students and family and, certainly, the urgency to address contents that problematize the difficulties in facing the pandemic. Based on this, this article proposes to discuss, from a theoretical approach, how social issues aggravated by the arrival of COVID-19, such as access to basic sanitation and water, can be addressed in the Science class from narratives that emerge from the daily lives of the groups most affected by the new coronavirus. We believe, therefore, that it is possible to create a Science Education committed to its social role and engaged in facing the social inequalities aggravated in the pandemic. For this, we started from the intellectual contributions of Paulo Freire, bell hooks, Carolina Maria de Jesus and Conceição Evaristo in order to reflect on the importance of the resignification of the contents of Science Education.

Keywords: Science teaching. Registrations. Literature. Pandemic. 
NASCIMENTO, Brenda Iolanda Silva do; CARVALHO, Iago Vilaça de; COSTA, Fernanda Antunes Gomes da. A sala de aula no contexto de (Pós) pandemia: ressignificando conteúdos de Ciências a partir de textos escreviventes

\section{Introdução}

Afinal, a ciência e a arte são como margens de um mesmo rio. (COUTO, 2011, p. 60)

A chegada da COVID-19 ao Brasil impactou a forma como pensamos as nossas práticas pedagógicas e o local em que nossa sala de aula passou a ocupar, fazendo emergir uma urgente discussão acerca das aulas remotas, além das consequências disso para discentes e docentes. No entanto, não menos importante se mostra a pauta dos conteúdos a serem ministrados, ou melhor, da necessidade de ressignificar e de contextualizar a abordagem das temáticas discutidas nas disciplinas a partir da pandemia. Descartar o contexto pandêmico no eixo dos conteúdos seria desconsiderar o papel da formação cidadã que a escola assume e que, para tal, mediar currículo e leitura do mundo, do contexto atual, é de extrema importância.

Diante disso, acreditamos ser a Educação em Ciências fundamental na conjuntura atual, pois a chegada da pandemia também suscitou o debate sobre a importância da Ciência. Sendo assim, mais do que a construção e explanação dos conhecimentos científicos acerca da atual problemática, a Ciência, diante do atual contexto, pode potencializar e tecer diálogos a partir de desafios não superados, como por exemplo, o acesso ao saneamento básico e à água potável, bem como os impactos disso na realidade (pós) pandemia. Acreditamos ser a disciplina de Ciências potente para as discussões acerca do enfrentamento das desigualdades sociais, pois seus conteúdos, em diálogo com as experiências subjetivas da comunidade escolar, podem reafirmar o papel social da Educação em Ciências.

Assim, para esta problematização entre Ciência, Educação e Sociedade, é necessário trazer à tona narrativas da pandemia e também as narrações que emergem das vozes que representam a parte da população mais afetada pelos efeitos do agravamento social. Vozes que muitas vezes permanecem silenciadas também por nossos currículos. Essas narrativas podem mediar as discussões sobre a educação na (pós) pandemia, pois entendemos ser urgente repensar nossos conteúdos a partir do compromisso com o enfrentamento das desigualdades que esse episódio histórico vivido pela humanidade nos impôs. Um dos caminhos, sem dúvida, para a re-existência de um mundo melhor, será pela educação. Principalmente, pelo seu potencial de problematização da realidade e seus possíveis impactos no exercício da cidadania de forma consciente e engajada.

Afinal, a educação tem papel importante e potente no debate e no enfrentamento das desigualdades, por ser um direito e por ser via para promoção de outros direitos, como o acesso à saúde, por exemplo. Pensar práticas pedagógicas comprometidas com uma sociedade mais igualitária e verdadeiramente democrática em oportunidades é pensar a educação a partir do 
NASCIMENTO, Brenda Iolanda Silva do; CARVALHO, Iago Vilaça de; COSTA, Fernanda Antunes Gomes da. A sala de aula no contexto de (Pós) pandemia: ressignificando conteúdos de Ciências a partir de textos escreviventes

combate às assimetrias evidenciadas por esta crise global da atualidade. A Educação em Ciências, neste caso, já tem se mostrado como campo de conhecimento importante para a construção de percursos para uma formação não só meramente científica-tecnológica, mas também cultural.

Mas como mediar as demandas curriculares exigidas e a leitura de um mundo pandêmico a partir da Educação em Ciências? Apostamos ser a Literatura produzida por mulheres um entrelugar possível para promover esse diálogo. Conceição Evaristo (2016), escritora e intelectual negra, cunha o termo "escrevivência" em sua produção literária. Esse termo nos possibilita pensar a importância de enxergarmos a literatura para além de uma disciplina escolar. Literatura como um caminho promissor, entre ficção e realidade. Literatura engajada à problematização daquilo que o texto literário pode provocar quando tecido a partir das vivências dos sujeitos que são mais vulneráveis às consequências dos agravamentos sociais. A obra desta autora nos apresenta contextos de vidas marcados pelas relações interseccionais de gênero, de raça, entre outros, que atravessam as experiências subjetivas das personagens. Para Conceição Evaristo, seus textos escreviventes nascem, principalmente, de vozes-mulheres negras (EVARISTO, 2008).

Acompanhamos, pelas notícias correntes, como as mulheres foram atingidas de forma mais severa pela pandemia. Aspectos de vulnerabilidade social, como desemprego, violência, aumento da pobreza e falta de acesso aos serviços de saúde e saneamento básico impactam mais vidas femininas neste momento. Portanto, fazer emergir as vozes de mulheres, pelas narrativas reais e pelas ficcionais, é caminho potente para contextualizar conteúdos que promovem reflexões acerca da pandemia e das desigualdades sociais em nossa sala de aula também de Ciências. Portanto, o que textos que narram as experiências humanas plurais podem denunciar e anunciar dentro do contexto da Educação em Ciências? O que apontam como possibilidade de construção de um mundo outro mais justo e igualitário? Como isso pode ser lido na sala de aula na (pós) pandemia?

\section{Por entre narrativas da pandemia}

Entre as muitas orientações acerca das medidas de prevenção ao novo coronavírus, temos a higiene pessoal e da casa como de suma importância, principalmente o ato de lavar as mãos. No entanto, em um país marcado pela desigualdade social como o nosso, a falta de saneamento básico ainda se mostra latente na realidade, sendo a falta de acesso à água um agravante nas taxas de contágio da COVID-19. Em reportagem (SILVEIRA, 2020) publicada em portal de grande circulação midiática, encontramos dados significativos oriundos do PNAD- IBGE de 2018: 16\% da população brasileira não tem acesso à água, 37\% vive em áreas sem coleta de esgoto e 5,6 \% da população se encontra vivendo com mais de 3 moradores por dormitório. 
NASCIMENTO, Brenda Iolanda Silva do; CARVALHO, Iago Vilaça de; COSTA, Fernanda Antunes Gomes da. A sala de aula no contexto de (Pós) pandemia: ressignificando conteúdos de Ciências a partir de textos escreviventes

Como agravante aos números acima, temos a ONU News (2019) a divulgar a seguinte informação antes da chegada da COVID-19: mulheres autodeclaradas indígenas, pardas e pretas são as que têm mais dificuldades de acesso à água no Brasil, nos fazendo perceber que a discussão de gênero e de raça se mostra ainda mais urgente na pandemia. Sendo as mulheres mais suscetíveis aos trabalhos domésticos e ao cuidado de pessoas próximas quando familiares adoecem, essa informação passa ser ainda mais grave. Diante dessas situações expostas, percebemos que o acesso à água e ao saneamento básico se torna vital, visto que muitas mulheres se encontram em um quadro de sobrecarga não apenas pelos serviços domésticos e de cuidado, mas por terem suas vidas expostas à contaminação do vírus e de outros fatores de adoecimento.

Portanto, diante dessa problematização, narrativas da pandemia que tragam à tona a pauta do saneamento básico e o acesso à água para se discutir as estratégias de prevenção ao novo coronavírus na escola, por exemplo, precisam também trazer a face da realidade social de quem é mais afetado diariamente pela questão. Esse debate pode ser ainda potencializado se lançarmos a ele uma estratégia de leitura capaz também de ser discurso contra-hegemônico dentro do conteúdo abordado. A Educação em Ciências em diálogo com a Literatura pode mostrar que a produção do conhecimento deve, ainda mais na atualidade, estar inteiramente comprometida com os desafios sociais.

Mas não seria a Ciência e a Literatura diferentes campos de saberes com distintos conteúdos para sala de aula? Para o escritor e biólogo moçambicano Mia Couto (2011, p. 58), “a ciência e a literatura podem pôr em causa as ideias arrumadas que apresentam a Terra, a Vida e o Ambiente como entidades feitas, exteriores ao Homem". Portanto, precisamos, enquanto educadores, atravessados pela pandemia e por suas consequências, também pensar as disciplinas ministradas de forma engajada com o contexto emergente, assim como dialogando, cada vez mais, com a pluralidade da produção de conhecimento. Abraçar as possibilidades que se apresentam para uma formação humana e cidadã é fundamental para isso.

Conceber, como Mia Couto (2011) diz, a ciência e a arte, a arte literária produzida por mulheres negras no caso desta proposta, como margens de um mesmo rio é entender que "o ato de ensinar exige a existência de quem ensina e de quem aprende" (FREIRE, 2016, p 55). Acreditamos, a partir do contexto pandêmico atual, portanto, que não poderemos mais ignorar essas experiências de re-existências impostas pelas desigualdades em nossos conteúdos. O desafio é a seguinte questão: como promover esse caminho?

Sendo assim, trazemos, para este texto, propostas para uma Educação em Ciências consciente do seu papel social e político. E isso pode ser possível a partir das narrativas que 
NASCIMENTO, Brenda Iolanda Silva do; CARVALHO, Iago Vilaça de; COSTA, Fernanda Antunes Gomes da. A sala de aula no contexto de (Pós) pandemia: ressignificando conteúdos de Ciências a partir de textos escreviventes

emergem da pandemia e das narrativas femininas que emergem de textos escreviventes, tais como a narrativa de Conceição Evaristo e a de Carolina Maria de Jesus.

\section{O papel social e político da Educação em Ciências}

A ressignificação do presente tem exigido de nós a compreensão sobre de que forma a Educação em Ciências pode contribuir para que possamos construir percursos de superação na (pós) pandemia. A sala de aula, também lugar de sonhos e de possibilidades, requer que possamos ser criativos para desenvolvermos reflexões e ações práticas que assegurem que este espaço possa continuar exercendo sua importância na vida de tantas pessoas, principalmente, daquelas que encontram ali a possibilidade de ser mais no mundo e com o mundo, como bem lembra intelectuais como Paulo Freire e bell hooks.

Segundo Paulo Freire (1996), diante da realidade complexa em que os fatalismos se apresentam, na forma da fome, da miséria, do desemprego, da pobreza, das doenças, entre outros, a educação emerge de forma a confrontar o que se apresenta como "inevitável” às populações mais vulnerabilizadas. Até porque, se um dia acreditamos que o avanço científico e tecnológico seria suficiente para solucionar todos estes problemas, hoje, podemos perceber que nem sempre os frutos dessas conquistas têm se comprometido com a reparação das injustiças históricas. Portanto, a eterna reinvenção da sala de aula convoca a Educação em Ciências ao estabelecimento de um compromisso ético, de forma a lançar outros olhares para o que se tem trabalhado nos currículos escolares.

Se para Paulo Freire (1967), a educação como prática da liberdade busca questionar a realidade que é posta, também se faz verdade que o olhar para os conteúdos deve envolver a sensibilidade para se tecer diálogos com as histórias de vidas presentes na sala de aula. Como bem aponta a autora bell hooks (2013, p. 25), conceber "ensinar de um jeito que respeite e proteja a alma de nossos alunos é essencial para criar as condições necessárias para que o aprendizado possa começar de modo mais profundo e mais íntimo". Nesse movimento, as transgressões das fronteiras dos conhecimentos, que atravessam as subjetividades durante o processo pedagógico, posicionam a Educação em Ciências para além de uma proposta de formação de caráter meramente técnicocientífico.

A partir das reflexões propostas por Paulo Freire e bell hooks, é possível pensarmos em algumas questões relevantes para se considerar os possíveis desafios e impactos sociais a partir da Educação em Ciências diante deste cenário atual. Dentre alguns desafios a serem superados, podemos citar a presença de tendências tradicionalistas nos currículos de Ciências. Tendências que 
NASCIMENTO, Brenda Iolanda Silva do; CARVALHO, Iago Vilaça de; COSTA, Fernanda Antunes Gomes da. A sala de aula no contexto de (Pós) pandemia: ressignificando conteúdos de Ciências a partir de textos escreviventes

acabam operando para a fragmentação do conhecimento e distanciamento desta área de saber do campo social, do campo político e, assim, colocando as experiências subjetivas à parte do ensino e do aprendizado de conteúdos das aulas de Ciências. Além disso, a concepção de uma Ciência neutra e objetiva faz com que a Educação em Ciências, muitas vezes, se apresente de forma distanciada da complexidade das discussões sociais, de forma a focalizar uma formação técnico-científica que não leva em consideração a formação humana e cidadã (ARROYO, 1988). Nesse sentido, Paulo Freire nos alerta que, ao pensarmos em um processo educativo de qualidade, devemos considerar isto:

É preciso que saibamos que, sem certas qualidades ou virtudes como amorosidade, respeito aos outros, tolerância, humildade, gosto pela alegria, gosto pela vida, abertura ao novo, disponibilidade à mudança, persistência na luta, recusa aos fatalismos, identificação com a esperança, abertura à justiça, não é possível a prática pedagógico-progressista, que não se faz apenas com ciência e técnica. (FREIRE, 1996, p. 62).

Portanto, aprender e ensinar Ciências exige que possamos considerar todos esses elementos citados por Paulo Freire, reafirmando o papel político e social dos conteúdos existentes em seus currículos. Ao encontro das ideias de Paulo Freire, a autora e intelectual negra bell hooks (2013), ao pensar em uma pedagogia voltada para a prática da liberdade, mostra ser fundamental o exercício docente orientado por práticas antirracistas, antissexistas e anticoloniais/anticapitalistas. O desenvolvimento de um fazer pedagógico que tenha como compromisso ético o desmantelamento de estruturas de opressão, como o racismo e o sexismo, lança possibilidades para que os conteúdos de Ciências possam ser ressignificados e abordados de forma a confrontar os fatalismos presentes na sociedade, agravados nesta pandemia.

É importante levarmos isso em consideração, ou seja, questões sociais, visto que um dos conteúdos abordados nos currículos das disciplinas de Ciências é o tema do saneamento básico e do acesso à água, bem como suas implicações no meio ambiente e saúde pública. Com a chegada do novo coronavírus, percebe-se que as áreas mais afetadas pela propagação do vírus são as regiões onde o saneamento básico, assim como o acesso à água potável, se mostra ausente ou precário. De acordo com a ONU - Organização das Nações Unidas (2020), a luta pelo saneamento básico e água para todos vai ao encontro da luta pelos direitos humanos e de uma agenda de desenvolvimento sustentável. É importante dizer que no Brasil o acesso ao saneamento básico é direito constitucional previsto pela Lei no 11.445/2007 (BRASIL, 2007). Logo, é imprescindível que a abordagem desse conteúdo possa ser contextualizada com as dimensões sociais intrínsecas presentes, visto que a problemática do saneamento básico se apresenta de forma bastante atual e impacta de diversas formas o desenvolvimento da vida humana. 
NASCIMENTO, Brenda Iolanda Silva do; CARVALHO, Iago Vilaça de; COSTA, Fernanda Antunes Gomes da. A sala de aula no contexto de (Pós) pandemia: ressignificando conteúdos de Ciências a partir de textos escreviventes

Dessa forma, a Educação em Ciências exerce função importante nessa discussão, principalmente na ressignificação de conteúdos a partir do contexto pandêmico. Se olharmos alguns documentos nacionais, como a Base Nacional Comum Curricular (BNCC), podemos perceber que a abordagem dessa problemática tem sido pensada nas séries finais do Ensino Fundamental em que, dentre as inúmeras habilidades, uma que se destaca é

Interpretar as condições de saúde da comunidade, cidade ou estado, com base na análise e comparação de indicadores de saúde (como taxa de mortalidade infantil, cobertura de saneamento básico e incidência de doenças de veiculação hídrica, atmosférica entre outras) e dos resultados de políticas públicas destinadas à saúde. (BRASIL, 2017, p. 347).

Sendo assim, a busca por abordagens educacionais sensíveis que possam potencializar a interpretação acerca das condições de saúde à luz de uma pedagogia engajada, como propõe bell hooks, pode fomentar nas séries finais do Ensino Fundamental, por exemplo, uma consciência crítica e comprometida com a superação das iniquidades sociais, para além do domínio de conhecimentos técnico-científicos. Para Paulo Freire (1967), a educação como ato político e, portanto, fundamental para existência de espaços de transformação social, encontra nas vozes das pessoas oprimidas os saberes necessários para interpretar o mundo através de uma perspectiva que busca atender as demandas das classes populares e não das grandes elites econômicas. Portanto, isso impele à Educação em Ciências o compromisso com as experiências de vida presente nesses contextos de crise, incluindo agora o pandêmico.

Em um país em que muitas mulheres declaram não ter acesso à água tratada e relatam não ter acesso à infraestrutura sanitária, se torna fundamental pontuar as experiências subjetivas dessas mulheres a partir dessa problemática, principalmente, de mulheres negras já, que são as mais afetadas pelas dinâmicas dessa realidade. Mais do que números, são vidas que devem ser levadas em consideração ao problematizarmos de que forma podemos pensar o papel social e político da Educação em Ciências na abordagem deste tipo de conteúdo na sala de aula na pandemia e após a pandemia. Assim, não só proporcionar a aprendizagem de conteúdos científicos, como também contribuir para uma formação humana através de uma cultura de engajamento mútuo a partir da sala de aula. Que caminho de abordagem então pode ser possível?

Apostamos na palavra insubmissa das mulheres, em especial, das mulheres negras que vêm sofrendo sistematicamente com as mazelas sociais históricas. Por meio do encontro com a Literatura de autoria feminina negra, acreditamos que a Educação em Ciências possa promover diálogos sobre as transgressões necessárias aos conhecimentos, de forma a desconstruir o fazer pedagógico conteudista e apático diante das insurgências do momento atual. A busca pela formação humana e cultural nas aulas de Ciências pode encontrar, nas palavras silenciadas de mulheres, o 
NASCIMENTO, Brenda Iolanda Silva do; CARVALHO, Iago Vilaça de; COSTA, Fernanda Antunes Gomes da. A sala de aula no contexto de (Pós) pandemia: ressignificando conteúdos de Ciências a partir de textos escreviventes

conhecimento social e político acerca das vidas subalternizadas que tanto são impactadas pela falta do acesso a direitos fundamentais humanos, como o saneamento básico e a água. Afinal, se a Ciência e a Literatura são margens de um mesmo rio, quais são os possíveis impactos resultantes dessa confluência?

A partir da intelectualidade de mulheres negras, como Carolina Maria de Jesus e Conceição Evaristo, buscamos aqui compreender as dimensões políticas e sociais da ressignificação dos conteúdos em Ciências para sala de aula na (pós) pandemia. Reflexões essas tecidas no intuito de colaborar para que a Educação em Ciências possa assumir seu papel social e político frente às injustiças de gênero, de raça e de classe. E que encontre, nessas vozes de mulheres, caminhos para a superação das injustiças sociais que podem e devem ser construídos diariamente nas salas de aula do nosso país. Como bem lembra Paulo Freire (1996), o aprendizado deve ir além da ciência e da técnica. Através da abordagem dialógica entre Literatura e Ciência, buscamos enfatizar a recusa aos fatalismos, através da postura comprometida com o enfrentamento às injustiças e da identificação da esperança como pilar fundamental para o exercício do papel social e político da Educação em Ciências.

Textos escreviventes: Carolina Maria de Jesus e Conceição Evaristo na Educação em Ciências em contexto de (Pós) pandemia

Considerando as reflexões abordadas acerca das desigualdades e do contexto pandêmico da COVID-19, podemos pensar nos inúmeros impactos às condições de vida dos brasileiros, em especial das mulheres negras - bem como para o corpo social escolar - a partir do conceito de situações-limites. Segundo as ideias pedagógicas de Paulo Freire, estas situações são "dimensões concretas e históricas de uma dada realidade” (FREIRE, 1977, p. 120). Para o autor, são situações que obstaculizam o processo de humanização, mas que não são "situações insuperáveis além das quais nada mais existiria. Elas não constituem um freio como qualquer coisa que não possa ter possibilidades de superação". (FREIRE, 1977, p. 120).

Com isto, o autor nos leva a refletir sobre estas problemáticas não como situações intransponíveis, mas como circunstâncias propícias para o exercício da cidadania e do pensamento crítico. Ainda de acordo com Freire (1977, p. 120), no “início da percepção crítica, na mesma ação se desenvolve um clima de esperança e de fé que leva os homens a se empenharem na superação das situações-limites". Ou seja, o reconhecimento das situações de opressão experienciadas pelos diferentes sujeitos sociais marca um importante passo para o início da luta pela humanização. 
NASCIMENTO, Brenda Iolanda Silva do; CARVALHO, Iago Vilaça de; COSTA, Fernanda Antunes Gomes da. A sala de aula no contexto de (Pós) pandemia: ressignificando conteúdos de Ciências a partir de textos escreviventes

Dessa forma, atribuir à sala de aula e aos demais ambientes pedagógicos o compromisso com o desenvolvimento desta percepção crítica sobre a realidade é um caminho para o desenvolvimento da justiça social. Sendo assim, consideramos a Educação em Ciências como um campo de produção do conhecimento que permite o estímulo a práticas e a visões questionadoras da realidade. E, ainda, reconhecemos a Literatura que emerge de vozes-mulheres-negras como uma linguagem capaz de potencializar esse efeito questionador ao evidenciar outras leituras de mundo.

É o caso da realidade expressa por Carolina Maria de Jesus em sua obra Quarto de Despejo (2014). Em seu relato, observamos as agruras vivenciadas no final da década de 1950, na favela do Canindé, antiga comunidade estabelecida às margens do Rio Tietê, onde hoje se encontra a Marginal Tietê na capital paulista. A autora desabafa suas misérias e os desafios como mulher negra, semianalfabeta, mãe solo de três crianças e catadora de papel e outros materiais reciclados.

Mais do que um retrato e um diagnóstico da pobreza, Quarto de Despejo (2014) nos convida a refletir sobre a realidade complexa da favela. Uma realidade que coleciona, de um lado, sonhos, lutas e pulsões de vida dos moradores da favela e, do outro, a falta de recursos e de infraestrutura, e as assimetrias sociais. Numa passagem, datada do dia nove de julho de 1958, Carolina diz:

Eu já estava deitada quando ouvi as vozes das crianças que estavam passando cinema na rua. Não acreditei no que ouvia. Resolvi ir ver. Era a Secretaria de Saude. Veio passar um filme para os favelados ver como é que o caramujo transmite a doença anêmica. Para não usar as aguas do rio [Tietê]. Que as larvas desenvolve-se nas aguas. (...) Até a agua... que em vez de nos auxiliar, nos contamina. Nem o ar que respiramos, não é puro, porque jogam lixo aqui na favela.

Mandaram os favelados fazer mictorios. (JESUS, 2014, p. 57).

Podemos perceber a crítica da autora ao fato de um bem essencial para a vida, como a água, não ser acessível para o uso dos moradores da localidade. Em nota do editor, a doença em questão é apontada como sendo a esquistossomose. É interessante perceber ainda que, na sequência do diário, alguns dias depois desse episódio, Carolina de Jesus relata que seus filhos apresentavam sintomas da doença. Ou seja, mesmo com o trabalho de conscientização, os recursos hídricos permaneceram precarizados, o que levou as crianças a adoecerem.

Considerando ainda os acontecimentos citados, dez dias depois, Jesus (2014) narra, em sua obra, que um de seus filhos não tem calçados para ir à escola e que, mesmo assim, saiu para estudar. A falta de calçados aparece recorrentemente na obra — inclusive na abertura do livro — o que representa uma situação constante de vulnerabilidade à saúde. Sendo assim, podemos perceber que, mesmo orientados sobre como utilizar a água de forma a prevenir doenças, os filhos de Carolina, 
NASCIMENTO, Brenda Iolanda Silva do; CARVALHO, Iago Vilaça de; COSTA, Fernanda Antunes Gomes da. A sala de aula no contexto de (Pós) pandemia: ressignificando conteúdos de Ciências a partir de textos escreviventes

e possivelmente outras crianças, ainda se encontravam expostas aos vetores desta e de outras enfermidades.

Quando estas e outras situações-limites são reconhecidas durante a leitura, oportunidades de debates outros vêm à tona para os conteúdos de Ciências, dando materialidade ao abstrato e também ressignificando o contexto sanitário atual à luz de acontecimentos de uma outra época e de um outro contexto. É possível ainda, por meio desta denúncia, abrir espaço para diferentes problematizações que podem contemplar as demandas sociais da população menos abastada.

Além disso, podemos ainda ponderar sobre o acesso e o incentivo a outras visões de mundo por meio da arte e da cultura. Na mesma passagem de Quarto de Despejo, Jesus (2014) demonstra surpresa ao ouvir sobre a sessão de cinema realizada pela Secretaria de Saúde, cujo objetivo era informar sobre a temática da esquistossomose. Outras sessões de cinema aparecem no diário, no entanto, promovidas por agências religiosas e com intuito catequético. Não são relatadas sessões cuja prerrogativa fosse de incentivar a arte e a cultura em suas múltiplas possibilidades.

Queremos dizer com isto que não apenas ações sazonais, envolvendo temas sanitários, podem ser caminhos para a promoção da saúde e priorizadas pela Educação em Ciências. Enfrentar a intensificação das doenças não se restringe apenas a educar para a prevenção, mas discutir infraestrutura e saneamento básico para tornar os espaços salutares, bem como investir em outras formas de garantir a dignidade humana a partir da educação, da cultura e da arte.

Outra situação de vulnerabilidade, desta vez ficcionalizada pela autora e intelectual negra Conceição Evaristo, é o desalojamento dos moradores da favela, na obra Becos da memória:

\footnotetext{
Os tratores da firma construtora estavam cavando, arando a ponta norte da favela. Ali, a poeira se tornava maior e as angústias também. Algumas famílias já estavam com ordem de saída e isto precipitava a dor de todos nós.

$[\cdots]$

Aqueles tratores trariam tanta tristeza, trariam desgraça até. E naquela noite aconteceria uma. (EVARISTO, 2017, p. 71-72).
}

Este trecho antecede um acidente fatal envolvendo os referidos tratores, usados para o desalojamento. Na sequência da obra a autora, lemos:

[...] Já haviam-se passado quase quatro meses. Os tratores estavam no mesmo lugar, de pernas para cima [...] O barro [da obra] assentara e, como o terreno era em declive, tinha se tornado uma pista escorregadia. As crianças, por não terem brinquedos prontos, acabavam sendo muito criativas. Com isso arrumavam tábuas, empoleiravam-se em cima, e vinham pelo morro abaixo. Era uma brincadeira perigosa, mas, moleques como eram, só viviam em perigo. Se não conseguissem desviar-se, bateriam de cara e tudo em cima do trator. Foi isso que aconteceu. (EVARISTO, 2017, p. 80).

Nesse sentido, problematizar as dificuldades que circundam a temática habitacional, a garantia à residência e à proteção física dos cidadãos também pode ser discussão que perpassa pela 
NASCIMENTO, Brenda Iolanda Silva do; CARVALHO, Iago Vilaça de; COSTA, Fernanda Antunes Gomes da. A sala de aula no contexto de (Pós) pandemia: ressignificando conteúdos de Ciências a partir de textos escreviventes

Educação em Ciências voltada para a cidadania. Da mesma forma, fazendo um paralelo com o contexto pandêmico, ensinar as medidas profiláticas se fazem imperativas para o combate ao novo coronavírus. Entretanto, defender a humanização das condições de habitação e de segurança, que zelam pela integridade física dos cidadãos, é caminho de combate ao avanço de mortes pelo COVID-19, na medida em que um corpo fragilizado ou exposto a condições adversas se torna mais suscetível ao adoecimento. Vale lembrar ainda que a intensificação dos casos de COVID-19 e a ocupação demasiada de leitos, assim como a falta de condições adequadas de trabalho aos profissionais da saúde, levam a uma fragilização do sistema de saúde, dificultando também o atendimento a outras enfermidades.

Queremos dizer com isso que, ao considerar as potencialidades do diálogo entre Literatura e Educação em Ciências, pensamos não bastar que os conceitos científicos curricularizados sejam ensinados mecanicamente nessas disciplinas durante / depois da pandemia. Em um momento em que grandes expectativas estão depositadas na Ciência e nas pesquisas para a descoberta, verificação e distribuição de tratamentos e/ou curas para as doenças epidêmicas, buscar também soluções para os problemas não superados (situações-limites) é comprometer-se com a vida humana e com o bem-estar de todos, em especial dos mais afetados pelos problemas socioeconômicos, raciais e de gênero.

Em diálogo com isto, podemos pensar ainda na possibilidade de valorização de diferentes narrativas, em sala de aula, e na construção de um ambiente acolhedor e favorável para a aprendizagem. Sobre isso, bell hooks aborda, em Ensinando pensamento crítico (2020), o comprometimento da prática docente com a pedagogia engajada que para ela "é uma estratégia de ensino que tem por objetivo recuperar a vontade dos estudantes de pensar e a vontade de alcançar a total autorrealização" (HOOKS, 2020, p. 33). Mas para a autora, o pensamento crítico não demanda apenas o envolvimento dos estudantes, mas de todos os sujeitos presentes em sala de aula, especialmente dos professores.

Para que seja estabelecido um ambiente favorável para o pensamento crítico e para a educação como prática da liberdade, os docentes devem estar abertos a aceitar e acolher diferentes pontos de vista, reconhecendo que não estão sempre certos e que o conhecimento não é estático. Dessa forma, além de permitir que o conteúdo tenha maior propósito em sala de aula, é estabelecida uma comunidade de aprendizagem, em que a amorosidade e a liberdade de pensamento e de expressão podem potencializar o processo formativo (HOOKS, 2020).

Em contrapartida, nos ambientes onde a curiosidade e o espírito crítico não são fomentados, o processo educativo torna-se um ato individual e solitário, em que os alunos não se 


\section{Dialogia}

NASCIMENTO, Brenda Iolanda Silva do; CARVALHO, Iago Vilaça de; COSTA, Fernanda Antunes Gomes da. A sala de aula no contexto de (Pós) pandemia: ressignificando conteúdos de Ciências a partir de textos escreviventes

sentem seguros para alimentar o desejo pelo conhecimento e de participar ativamente. A exemplo disto, podemos citar a seguinte passagem de Becos da memória (2017), em que a personagem principal, Maria-Nova, recorda uma experiência a dialogar com a problematização tecida. Ao mirar os festejos, a alegria e o samba que inundava a noite da favela, a menina começa a divagar

em um pensamento longínquo e próximo ao mesmo tempo. Duas ideias, duas realidades, imagens coladas machucavam-lhe o peito. Senzala-favela. Nesta época, ela iniciava seus estudos de ginásio. Lera e aprendera também o que era casa-grande. Sentiu vontade de falar à professora. Queria citar, como exemplo de casa-grande, o bairro nobre vizinho e como senzala, a favela onde morava. Ia abrir a boca, olhou a turma e a professora. Procurou mais alguém que pudesse sustentar a ideia, viu a única colega negra que tinha na classe. Olhou a menina, porém, ela escutava a lição tão alheia como se o tema escravidão nada tivesse a ver com ela. Sentiu certo mal-estar. Numa turma de quarenta e cinco alunos, duas alunas negras, e, mesmo assim, tão distantes uma da outra. Fechou a boca novamente, mas o pensamento continuava. Senzala-favela, senzala-favela! (EVARISTO, 2017, p. 72-73).

Aqui, é apresentado um ambiente escolar atravessado pela desigualdade racial. Um ambiente que não acolhe Maria-Nova, pela falta de colegas negros, já que a outra aluna negra não expressa a mesma inquietação que ela. Dessa forma, coagida pelo discurso da professora e pela indiferença de sua colega, Maria-Nova cala sua constatação quanto à manutenção das relações de poder do sistema político-econômico, baseado na hierarquia racial, que sustenta as desigualdades. O que poderia ser diferente se o ambiente da sala de aula fosse mobilizado como uma comunidade que acolhe as narrativas silenciadas? Inquietação constante.

Sendo um texto escrevivente, a obra ficcional de Conceição Evaristo (2017), apesar de não se comprometer com a realidade de forma literal, não renuncia totalmente os acontecimentos reais da vida. Por isso, podemos ler o "mal-estar", citado pela personagem, como sendo o mesmo que aflige estudantes negras e negros, que não percebem a escola e a sala de aula como um local acolhedor de suas subjetividades. Ou ainda, como um local de possibilita a transformação social de si e das suas narrações. Da mesma forma, uma compreensão possível para este texto ficcional é a de uma crítica ao ensino tradicional, que não permite explorar esta e outras narrativas que podem emergir da experiência pessoal dos estudantes.

Por fim, reforçamos a hipótese das potencialidades do diálogo entre o científico e o ficcional, entre Educação em Ciências e a Literatura que emerge de vozes-mulheres silenciadas (EVARISTO, 2008). A interlocução destas duas áreas do conhecimento pode apresentar diferentes percursos, permitindo o efeito de dinamismo que o aprendizado pode revelar. Por meio deste reconhecimento das narrativas e das subjetividades, enxergamos uma oportunidade para também valorizar as vivências que perpassam a sala de aula na (pós) pandemia, fortalecendo princípios como igualdade, união, liberdade de expressão e a valorização do aprendizado que, segundo hooks (2020), são essenciais para uma de educação democrática, engajada e pensada como prática da liberdade. 
NASCIMENTO, Brenda Iolanda Silva do; CARVALHO, Iago Vilaça de; COSTA, Fernanda Antunes Gomes da. A sala de aula no contexto de (Pós) pandemia: ressignificando conteúdos de Ciências a partir de textos escreviventes

\section{Considerações finais}

Ao retomarmos o pensamento de Paulo Freire e de bell hooks, podemos perceber que, a partir das reflexões tecidas no presente texto, buscamos corroborar com as discussões que permeiam as tentativas de atender às demandas e aos desafios impostos à profissão docente na atualidade. Certamente, estes desafios se apresentam de diferentes formas e impactam de diversas maneiras tanto a vida quanto o processo educativo. Pensando nisso, o ressignificar dos conteúdos, mediado pelo diálogo entre a Literatura feminina negra e a Educação em Ciências, para abordar os diferentes atravessamentos sociais causados pela COVID-19, pode se configurar não apenas como uma possibilidade de formação humana e cultural, mas também como percurso para construção de uma comunidade de aprendizagem. Ou seja, espaço em que educadores e educandos constroem juntos, na sala de aula, o ensino e a aprendizagem a partir do engajamento coletivo em prol da justiça social.

Certamente as análises construídas aqui não encerram as possibilidades que os textos literários e os conteúdos em Ciência têm a oferecer. Por isso, as problematizações apontadas podem impulsionar novas inferências e perspectivas para se pensar a atual conjuntura na sala de aula. Como campos do saber que despertam para o novo e para a potência criativa, pensamos a interação entre a Literatura e a Educação em Ciências como caminho para a abertura dialógica e pedagógica do processo formativo discente / docente e para uma educação comprometida com as pautas sociais.

Através do diálogo entre estes diferentes campos, que atravessam as subjetividades presentes na sala de aula, as possibilidades de discussão acerca do conteúdo do saneamento básico e do acesso à água lançam percepções para fatores correlacionados, como a fome, a pobreza, o adoecimento, o acesso à educação, entre outros. Situações estas que emergem do cotidiano retratado nas obras de Carolina Maria de Jesus (2014) e de Conceição Evaristo (2017), tão próximas de cotidianos da atual realidade. De fato, os conhecimentos oriundos do lugar social retratado pelas autoras refletem as condições subalternizadas em que a maioria das mulheres negras se encontram nesse país, principalmente, durante esses tempos de pandemia. Estes conhecimentos que emergem da Literatura de autoria feminina negra em consonância com a Educação em Ciências podem proporcionar um processo educativo que tece novos significados para os conteúdos. Portanto, ressignificar conteúdos de forma a enfatizar o caráter social e político da Educação em Ciências é (re)pensar a Educação em tempos de pandemia. 


\section{Dialogia}

NASCIMENTO, Brenda Iolanda Silva do; CARVALHO, Iago Vilaça de; COSTA, Fernanda Antunes Gomes da. A sala de aula no contexto de (Pós) pandemia: ressignificando conteúdos de Ciências a partir de textos escreviventes

\section{Referências}

ARROYO, Miguel. A função social do ensino de ciências. Em aberto, Brasília, ano 7, v. 7, n. 40, p. 3-11, out/dez. 1988.

BRASIL. Lei $n^{0} 11.445$, de 05 de janeiro de 2007. Estabelece diretrizes nacionais para o saneamento básico [...] e dá outras providências. Diário Oficial da União, jan. 2007.

BRASIL. Ministério da Educação. Base nacional comum curricular. Brasília, DF:

MEC, 2017. Disponível em: http://basenacionalcomum.mec.gov.br/. Acesso em: 27 set. 2020.

COUTO, Mia. E se Obama fosse africano? São Paulo: Companhia das Letras, 2011

EVARISTO, Conceição. Poemas da recordação e outros movimentos. Belo Horizonte: Nandyala, 2008.

EVARISTO, Conceição. Insubmissas lágrimas de mulheres. 2. ed. Rio de Janeiro: Malê, 2016.

EVARISTO, Conceição. Becos da memória. 3. ed. Rio de Janeiro: Pallas, 2017.

FREIRE, Paulo. Educação como prática da liberdade. Rio de Janeiro: Paz e Terra, 1967.

FREIRE, Paulo. Pedagogia do oprimido. Rio de Janeiro: Paz e Terra, 1977.

FREIRE, Paulo. Pedagogia da autonomia: Saberes necessários à prática educativa. São Paulo: Paz e Terra, 1996.

FREIRE, Paulo. À sombra desta mangueira. Rio de Janeiro: Editora Paz e Terra, 2015.

FREIRE, Paulo. Professora sim, tia não: cartas a quem ousa ensinar. 26. ed. São Paulo: Paz e Terra, 2016.

HOOKS, bell. Ensinando a transgredir: a educação como prática da liberdade. 2. ed. São Paulo: WMF Martins Fontes, 2013.

HOOKS, bell. Ensinando pensamento crítico: sabedoria prática. São Paulo: Elefante, 2020.

JESUS, Carolina Maria de. Quarto de despejo: diário de uma favelada. 10 ed. São Paulo: Ática, 2014.

Mulheres negras são as mais afetadas pela falta de saneamento básico no Brasil. ONU News, Brasil, 8 jan. 2019. Disponível em: https://news.un.org/pt/story/2019/01/1654412. Acesso em: 26 set. 2020.

SILVEIRA, Daniel. Coronavírus e desafios à prevenção: Brasil tem 31,3 milhões sem água encanada e 11,6 milhões em casas 'superlotadas'. G1, Rio de Janeiro, 28 mar. 2020. Disponível em: https:/ /g1.globo.com/economia/noticia/2020/03/28/coronavirus-e-desafios-a-prevencaobrasil-tem-313-milhoes-sem-agua-encanada-e-116-milhoes-em-casas-superlotadas.ghtml. Acesso em: 26 set. 2020.

Relator diz que sem água e sem saneamento não haverá sociedades justas. ONU News, 28 jul. 2020. Disponível em: https://news.un.org/pt/story/2020/07/1721481. Acesso em: 28 set. 2020. 


\section{Dialogia}

NASCIMENTO, Brenda Iolanda Silva do; CARVALHO, Iago Vilaça de; COSTA, Fernanda Antunes Gomes da. A sala de aula no contexto de (Pós) pandemia: ressignificando conteúdos de Ciências a partir de textos escreviventes

Recebido em: 30 set. 2020/ Aprovado em: 26 nov. 2020

Cite como

(ABNT NBR 6023:2018)

NASCIMENTO, Brenda Iolanda Silva do; CARVALHO, Iago Vilaça de; COSTA, Fernanda Antunes Gomes da. A sala de aula no contexto de (Pós) pandemia: ressignificando conteúdos de Ciências a partir de textos escreviventes. Dialogia, São Paulo, n. 36, p. 205-219, set./dez. 2020. Disponível em: https://doi.org/10.5585/dialogia.n36.18319.

\section{American Psychological Association (APA)}

Nascimento, B. I. S., Carvalho, I. V., \& Costa, F. A. G. (2020, set./dez.). A sala de aula no contexto de (Pós) pandemia: ressignificando conteúdos de Ciências a partir de textos escreviventes. Dialogia, São Paulo, 36, p. 205-219. https://doi.org/10.5585/dialogia.n36.18319. 